\title{
Application of thermal imaging for detecting cold air leak location in cold storage
}

\author{
P. Pathmanaban', Shanmuga Sundaram Anandan², B. K. Gnanavel ${ }^{3}$, C. P. Murigan ${ }^{4}$ \\ ${ }^{1}$ Department of Automtobile Engineering, Velammal Engineering College, India \\ ${ }^{2,4}$ Department of Mechanical Engineering, Sree Sastha Institute of Engineering and Technology, India \\ ${ }^{3}$ Department of Mechanical Engineering, Saveetha Engineering College, India
}

\begin{tabular}{l} 
Article Info \\
\hline Article history: \\
Received Mar 3, 2020 \\
Revised Apr 24, 2020 \\
Accepted Jul 3, 2020 \\
\hline Keywords: \\
Cold storage \\
Image processing \\
Insulation problem \\
Thermal image
\end{tabular}

\begin{abstract}
Nowadays Cold storage has been playing an important role in preserving the perishable food products like fruits, vegetables, dairy products, fish, and meat etc. The major problem of cold storage is unwanted energy transmission during the operation. It is necessary to maintain the constant temperature during storing the products. There are different kinds of energy loss happening during the operation. One of the major causes is cold air leaking from the inside of the cold room to outside. It is due to poor insulation and improper maintenance of cold storage. It is very difficult to identify the exact location of the leak by the naked eye. In this research work, the cold storage was inspected with the thermal imaging system. Thermal cameras are highly sensitive to temperature and it can detect the variation of temperature ranging from $0.1{ }^{\circ} \mathrm{C}$. The measured temperatures are further converted into a colour based pattern. It is known as thermogram. These colour-based thermal patterns are further processed for identifying energy transmission location. It is done by applying various image processing methods such as histogram equalization, diffusion error, otsu thresholding and morphologic function. These techniques were applied to images of cold storages and exact cold air transmission locations were identified.
\end{abstract}

This is an open access article under the CC BY-SA license.

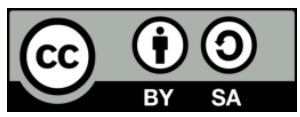

\section{Corresponding Author:}

P. Pathmanaban,

Department of Automtobile Engineering,

Velammal Engineering College,

Ambattur Red Hills Rd, Velammal Nagar, Surapet, Chennai, Tamil Nadu 600066, India.

Email: pathmanaban@velammal.edu.in

\section{INTRODUCTION}

Fruits and vegetables start to deteriorate or lose their quality in the following ways: change in weight, texture, flavour, colour, nutritional value and appearance at post-harvesting temperature and tends to reduce the shelf life of the product. Deterioration of the products depends on storage time and temperature [1]. Post-harvest cooling has the potential to reduce the respiratory activity, internal water loss and wilting of the products. It is also helpful to prevent degradation by enzymes, stops the production of a ripening agent, ethylene and the growth of microorganisms causing decay and pathogens. Moreover, postharvest cooling has the tendency to maintain the quality of the products for an extended period and supply it whenever required. It is the important benefit for growers and distributors. Recent day cold storages are highly capable of maintaining organoleptic qualities of the products and reduce spoilage and increase the shelf life [2]. Infiltration of water moist air into cold storage unit cause many problems which includes increased cost of running, defrosting the refrigeration system, mist formation [3]. Moreover, the temperature fluctuation causes weight loss and quality deterioration of the products [4]. Prediction and measurement of 
the cold air infiltration through doors by an analytical model has been proved in that Gosney model is better for predicting infiltration [5]. Cold storage consumes more energy than common buildings for maintaining lower temperatures. In the food industry, the refrigeration system is the only technology with the high cost and produce more emission, its approximately $1 \%$ of global GXG emissions [6]. It very well may be seen that the energy demand varies significantly from various kinds and areas of cold storages. Meanwhile, cold storages are the structures with huge warm mass, the transient energy utilization of which much depends on the variety of cooling heap of interior mass. To full fill the requirement, it is the necessity of cold storage exceptionally relies on its types and area. Hence, with an enormous energy devouring per storage volume, for the reasons to discover retrofit exponential of existing cold storage and better handling of the energy supply, an examination and quantization of the influencing variables of the transient energy consumption is important for users [7]. The innovation of phase change materials utilized in the cold room has incredible potential in energy storage and cost sparing under the foundation of peak and valley price of electricity [8].

In recent days the thermal imaging system has been used as an inspection tool for measuring different temperatures. It is working with the principle of infrared radiation (IR) to absorb the temperature and the radian energy of the object. Its major advantages are non-contact and not alter the temperature of the measuring objects. Moreover, it has the potential to measure wide temperature ranges, highly sensitive, low power consumption, and long life. In addition to that it is easy to operate, reliable and safe [9]. In Nondestructive testing, TI has been used to detect the material's defects and inhomogeneity by its strange thermal behavior [10]. Identification of a defect in surface and under the surface can evaluate by inspecting the contrast of the thermal image pixels. It is done by using the undamaged area pixel contrast as reference [11]. In civil engineering TI system is used to inspect and ensure the quality of the building by detecting the surface defects in structures [12]. In this research work, cold rooms are inspected with thermal camera and images are processed and analyzed with image processing tool in MAT lab.

\section{MATERIAL AND METHODS}

In this experimentation, two-ton capacity cold storage was used. The cold storage has been fully loaded with potatoes, which was collected from local agricultural lands in Chennai. Potatoes are stacked in the plastic bins and then it was placed in order. As per the regulatory guidance for storing temperature of potatoes, the room temperature was maintained $10^{\circ} \mathrm{C}$ with $90 \%$ humidity range [13]. The inside temperature was controlled by a control panel placed outside the cold storage. The environment temperature of Cold storage has also been maintained with a consistent temperature. The output and input parameters of the cold storage were regularly monitored and noted. A detailed description of the cold storage unit is provided in Table 1. To inspect the cold storage, FLIR E60 model camera used. Before taking the images, the outside environment of the cold storage was set as constant temperature. The automatic control system has been used to change ambient temperature and relative humidity of the cold storage. The calculation of the transmission heat created by walls, floor and ceiling requires information on thickness and type of isolation material used in construction of cold room, construction of building, physical specifications of the cold storage volume, inside and outside environment temperatures. Following equations were used to calculate transmission heat $[14,15]$.

$$
\begin{aligned}
& \mathrm{q}_{\mathrm{c}}=\mathrm{KA}\left(\mathrm{t}_{\text {out }}-\mathrm{t}_{\mathrm{i}}\right) \\
& \mathrm{q}_{\mathrm{c}}=\text { transmission heat at flat surface }(\mathrm{kCal}) \\
& \mathrm{K}=\text { Total heat transmission coefficient }\left(\mathrm{kCal} / \mathrm{hm}^{2 \circ} \mathrm{C}\right) \\
& \mathrm{A}=\text { Area of heat transmission }\left(\mathrm{m}^{2}\right) \\
& \mathrm{t}_{\mathrm{o}}=\text { Temperature of outside or neighbour volume }\left({ }^{\circ} \mathrm{C}\right) \\
& \mathrm{t}_{\mathrm{i}}=\text { Inside volume temperature }\left({ }^{\circ} \mathrm{C}\right) \\
& \frac{1}{\mathrm{~K}}=\frac{1}{\alpha \mathrm{i}}+\sum_{\mathrm{i}=1}^{\mathrm{n}} \cdot \frac{\mathrm{xi}}{\mathrm{li}}+\frac{1}{\alpha \mathrm{o}}
\end{aligned}
$$

Where:

$\alpha_{0}=$ Coefficient of heat transmission of outside surface $\left(\mathrm{kCal} / \mathrm{hm}^{2}{ }^{\circ} \mathrm{C}\right)$

$\alpha_{\mathrm{i}}=$ Coefficient of heat transmission of inside surface $\left(\mathrm{kCal} / \mathrm{hm}^{2}{ }^{\circ} \mathrm{C}\right)$

$\mathrm{x}_{\mathrm{i}}=$ Material thickness $(\mathrm{m})$

$\mathrm{l}_{\mathrm{i}}=$ Thermal conductivity $\left(\mathrm{kCal} / \mathrm{hm}{ }^{\circ} \mathrm{C}\right)$

The proposed method helps evaluate a leak of cold air through the introduction of image processing techniques. The following steps were taken to evaluate the exact location of the leak.

1. Acquisition of the image using a thermal camera.

2. Screening the image using filters.

3. Enhance the image. 
4. Compare the results

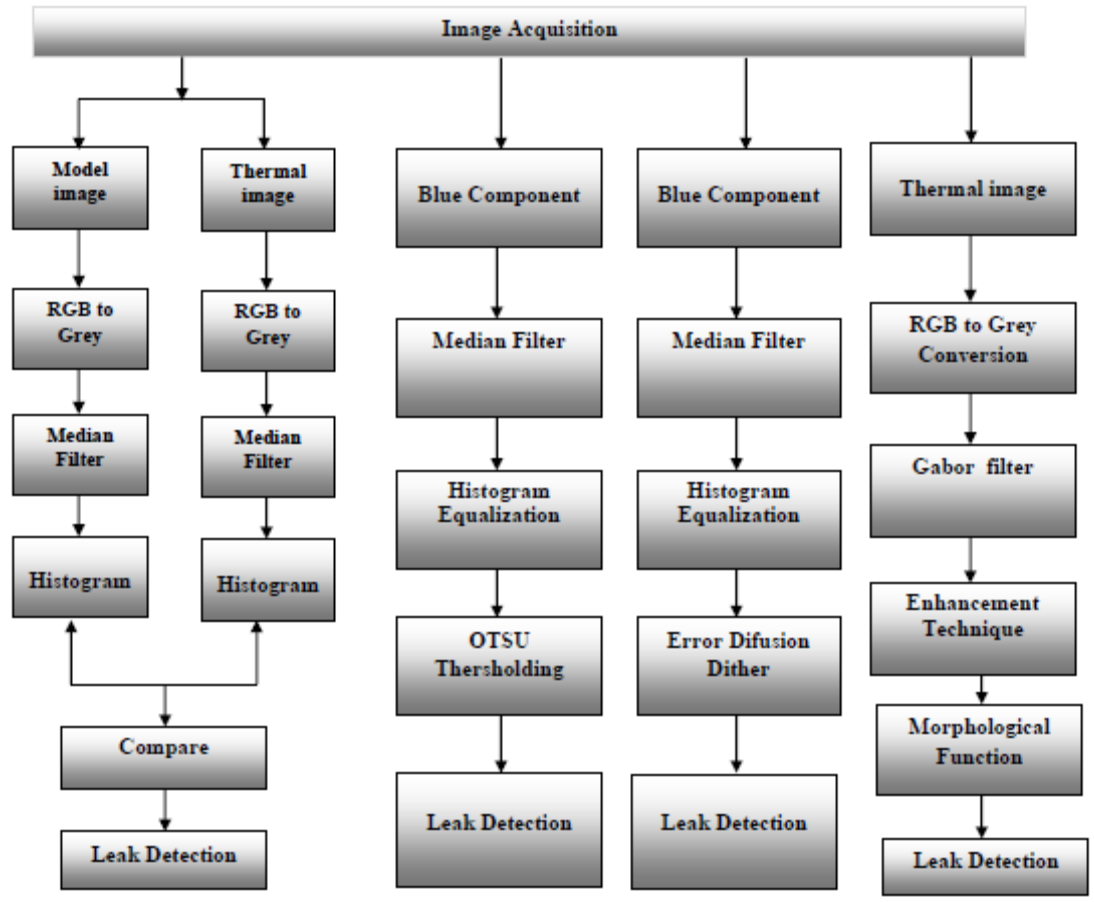

Figure 1. Flow chart the system

The image processing techniques currently evaluated are histogram, Otsu thresholding, diffusion error and morphological function (1) show the flow chart of the system. The purpose of this research is to detect a cold air leak location in a cold storage unit.

\section{FLOWCHART AND EXPLANATION}

\subsection{Image acquisition}

The quality of the thermal images depends on controllable parameters such as ambient temperature, airflow and lighting. It is necessary to maintain the temperature at $30^{\circ} \mathrm{C}$, without air draft and diffused lighting. Thermal camera has been used to inspect the cold storage after $24 \mathrm{hrs}$ of installation. The thermal camera switched to video mode and recorded the entire cold storage from the outside. It is observed that the thermal camera shows most of the region with yellow colour and some of the regions with a blue colour. Based on this variation the blue spot region is marked and images of that region were taken for further analysis. Thermal images were captured at where the low-temperature region is identified. Each image is analyzed and few images are selected for image processing.

\subsection{Histogram method}

Two sets of images are considered for the analysis-thermal cold storage image and trial image for training. The trial thermal pattern was generated using computational fluid dynamics software (Star CCM+). The trial image is generated such that, the colour blue depicts the lowest temperature and extends to the colour red which stands for the highest temperature [16]. The analysis was performed in the numerically generated image and then repeated for the thermal image of the cold storage

Table 1. The cold storage unit

\begin{tabular}{lcccccc}
\hline Image Name & Zeros & Non-Zeros & RMS Error & SNR & Median & Stddv \\
\hline Image1 (No leak) & 52 & 204 & 0 & 0.000 & 206 & $9.7 \mathrm{e}+002$ \\
Image2 (Moderate leak) & 0 & 218 & 65.37 & -9.94 & 193 & $4.3 \mathrm{e}+002$ \\
Image3 (Light Leak) & 38 & 256 & 54.01 & -7.53 & 185 & $5.5 \mathrm{e}+002$ \\
Image4 (SevereLeak) & 0 & 256 & 80.54 & -11.64 & 190 & $2.5 \mathrm{e}+002$ \\
\hline
\end{tabular}




\subsubsection{RGB to grey conversion}

RGB is converted into a greyscale image, which is the intensity image. This conversion occurs by eliminating hue and saturation and retaining luminance.

\subsubsection{Noise filtering}

The median filter is used in this paper for sorting out salt and pepper noise. It keeps the sharp edges and is a non-linear operation. For every input pixel $\mathrm{p}(\mathrm{x}, \mathrm{y})$, the value of the pixel is found, its median is identified and the value is assigned to output pixel $\mathrm{q}(\mathrm{x}, \mathrm{y})$. After acquiring the image, it is processed using the three types of processing techniques, namely histogram, Otsu thresholding and morphological function.

\subsection{Otsu thresholding method}

The acquired image is first converted in to a grey image. The red component is extracted from the image and filtered using a median filter.

\subsubsection{Median filter}

The median filter is used in this method for preserving the edges and to remove the salt and pepper noise. The process of the median filter is the replacing of each value with the median value of the neighbouring pixel. It is determined by first arranging all the pixel esteems from the window into numerical request, and after that supplanting the pixel being considered with the centre pixel esteem. The focal pixel is supplanted by the middle of pixels in the window.

\subsubsection{Histogram equalization}

The image is processed using histogram equalization which helps adjust the image intensities to enhance contrast.

Table 2. Histogram analysis

\begin{tabular}{llll}
\hline No & Image & Histogram value & Observation \\
\hline 1 & Image 1 & No peaks in the ranges less than 150 & Side wall \\
2 & Image 2 & Medium pixel values in <150 region & Moderate leak \\
3 & Image 3 & less pixel value in <150 region & Light leak \\
4 & Image 4 & More pixel values (peaks) in <150 region & severe leak \\
\hline
\end{tabular}

\subsubsection{Otsu thresholding}

In image binarisation, Otsu threshold method helps to reduce the grey level image to a binary image. In this method, all possible threshold values are iterated to calculate the spread of pixel value on both sides of the threshold value. The purpose is to find out the threshold value for classifying the is either leaking or nonleaking. According to OTSU method, minimizing 'within-class variance' is equal to maximizing 'between class variance' of the segmented image. However, maximizing 'between class variance' is less expensive than minimizing 'within-class variance'.

\subsection{Morphological process}

\subsubsection{Gabor filters}

The RGB image is converted to a grey image. The captured image is filtered using a Gabor filter. The Gabor filter converts the image to discrete value for getting the constant region of the image. Compared to other filters, the Gabor filter is primarily used for a low range of values. The filtered image is iterated for five iterations. This helps extract particular affected area for a clearer view.

\subsubsection{Enhancement techniques}

In this technique, there are two types - dilation and erosion. Dilation is the process which increases the white content of the image by adding pixels to the boundary of the object. Erosion is used to increase the black content of the image by removing the pixels from the boundary of the object. The small particles in the dilated image are eroded in the erosion process.

\subsubsection{Morphological function}

A morphological method identifies the shape and features of a cold air leaking area in a given image. The organizing component is set in every conceivable situation in the picture and it's contrasted and the relating neighbourhood of pixels. According to the output of the test, it identifies the image that fits or hits the neighbourhood pixels. Erosion strips one layer of both inner and outer boundaries. It avoids small 
details and enlarges holes and gaps between different regions. The boundaries are found by subtracting the eroded image from the original image. $\mathrm{x}=\mathrm{f}-(\mathrm{f}(\Theta) \mathrm{s})$, where $\mathrm{f}$ is an image of the regions, $\mathrm{s}$ is a $3 \times 3$ structuring element, and $\mathrm{x}$ is an image of the region boundaries [16]. Dilation adds one layer on both the inner and outer boundaries. It will fill in the gaps between the two regions.

\section{RESULT AND DISCUSSION}

The analysis is done with four images taken at different location of cold storage. Each image is taken separately and the results are observed using four methods and compared.

\subsection{Histogram method}

According to Figure 2, it was observed that the pixel intensity of image 1 (a) lies between above 150 to 255 range. It is due to a high number of bright sides by high temperatures. It is noted as no leak of cold air. At the same time pixel intensity of image 2 (b) has shown a light peak in the histogram at the range less than 150. It is due to darker regions of images caused by low temperatures. Similarly, the histogram of image 4 (d) shows more peaks in the lower range and image 3 (c) has a moderate peak in lower ranges. It is observed that the histograms show the cold leaking regions clearly by the distribution of pixel intensities.

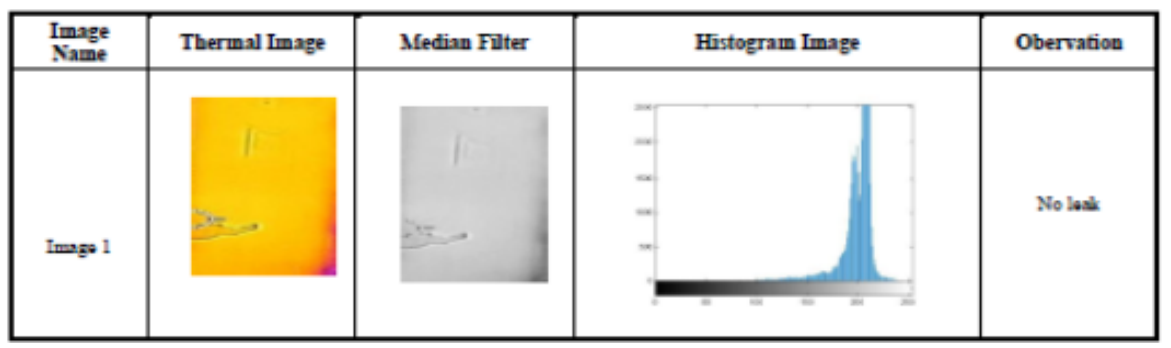

(a)

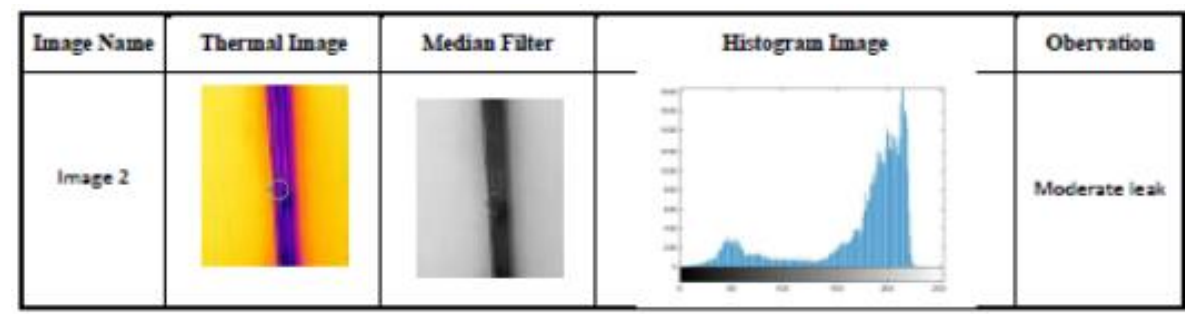

(b)

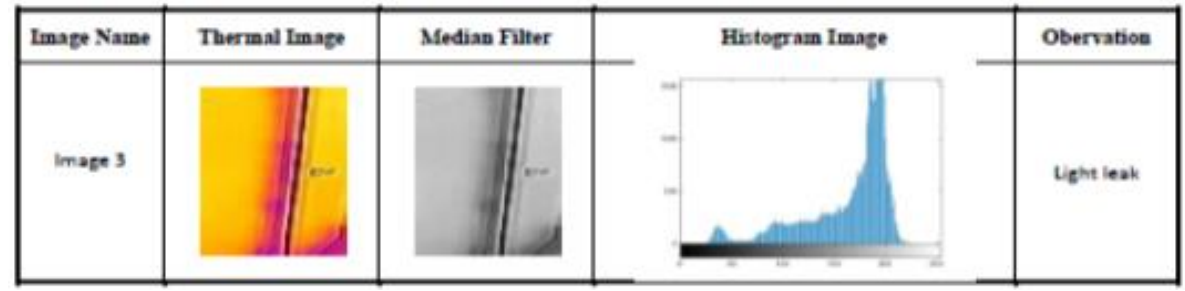

(c)

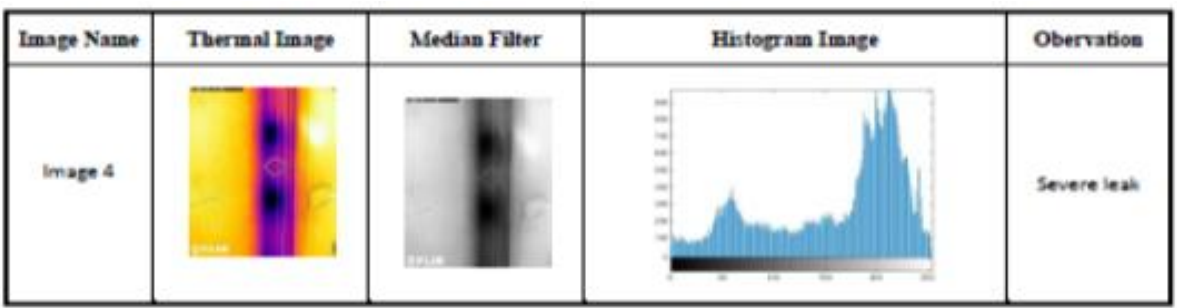

(d)

Figure 2. Histogram of the images 


\subsection{Otsu thresholding method}

According to Figure 3, the same images which has been used in the histogram method are processed with otsu thresholding. The result shows the image 4 (d) having more leaking regions than others. Image 1 (a) shows no leaking, similarly the images 2 (b) and image 3 (c) showing less and moderate leaking respectively.

\begin{tabular}{|c|c|c|c|c|c|c|}
\hline $\begin{array}{l}\text { Image } \\
\text { Name }\end{array}$ & Thernal Inage & $\begin{array}{c}\text { Blue } \\
\text { Component }\end{array}$ & Median Filter & $\begin{array}{c}\text { Histogram } \\
\text { Equalization }\end{array}$ & $\begin{array}{c}\text { OTSU } \\
\text { thresholding }\end{array}$ & Observation \\
\hline Image 1 & $\therefore$ & 5 & $\infty=$ & & & No leak \\
\hline
\end{tabular}

(a)

\begin{tabular}{|c|c|c|c|c|c|c|}
\hline $\begin{array}{c}\text { Image } \\
\text { Name }\end{array}$ & Thernal Image & $\begin{array}{c}\text { Blue } \\
\text { Component }\end{array}$ & Median Fiter & $\begin{array}{c}\text { Histogram } \\
\text { Equilization }\end{array}$ & OTSU thresholding & Observation \\
\hline Image 2 & & & & & & \\
\end{tabular}

(b)

\begin{tabular}{|c|c|c|c|c|c|c|}
\hline $\begin{array}{c}\text { Image } \\
\text { Name }\end{array}$ & Thermal Image & $\begin{array}{c}\text { Blue } \\
\text { Component }\end{array}$ & Median Filter & $\begin{array}{c}\text { Histogram } \\
\text { Equilization }\end{array}$ & $\begin{array}{c}\text { OTSU } \\
\text { thresholding }\end{array}$ & Observation \\
\hline Image 3 & & & & & & \\
\hline
\end{tabular}

(c)

\begin{tabular}{|c|c|c|c|c|c|c|}
\hline $\begin{array}{l}\text { Image } \\
\text { Name }\end{array}$ & Thermal Image & $\begin{array}{c}\text { Blue } \\
\text { Component }\end{array}$ & Median Filter & $\begin{array}{l}\text { Histogram } \\
\text { Equilization }\end{array}$ & $\begin{array}{l}\text { OTSU } \\
\text { thresholding }\end{array}$ & Observation \\
\hline Image 4 & & & & & & Severe leak \\
\hline
\end{tabular}

(d)

Figure 3. Thresholding method of images

\subsection{Error diffusion dither}

Same images were also used in this thresholding. After histogram equalization of all the images, error diffusion dither thresholding applied to all the images and the results are comparable. In this method, the exact location of the leak was identified. Image 4 Figure 4. shows more leaking region than other images. 


\begin{tabular}{|c|c|c|c|c|c|c|}
\hline $\begin{array}{l}\text { Image } \\
\text { Name }\end{array}$ & Thermal Image & $\begin{array}{c}\text { Blue } \\
\text { Component }\end{array}$ & Median Filter & $\begin{array}{l}\text { Histogram } \\
\text { Equalilization }\end{array}$ & $\begin{array}{l}\text { Error Difusion } \\
\text { Dither }\end{array}$ & Observation \\
\hline Image 4 & & 6 & & & & Severe leak \\
\hline
\end{tabular}

Figure 4. Error diffusion dither

\subsection{Morphological method}

According to Figure 5, the thermal image (a) is converted into a greyscale image, and the intensity of the image is noted (b). The grey image has undergone five iterations and all the stages are shown in (c). After iteration, the Fig.ure proceeds with the morphological process. For extracting the leak area, the iterated image analyses with the morphological process (dilation and erosion) (d). The leak location of the image is extracted and it is incorporated with the original image. This helps to identify the leak location without an expert's advice (e).

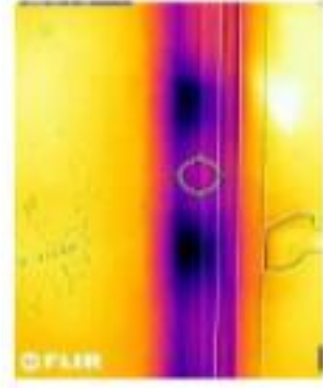

(a)

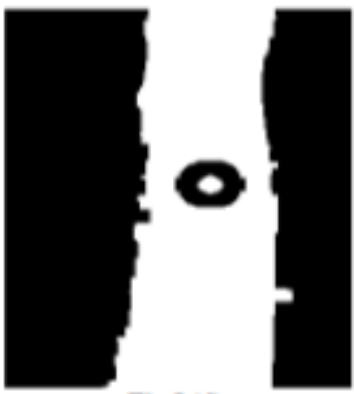

(d)

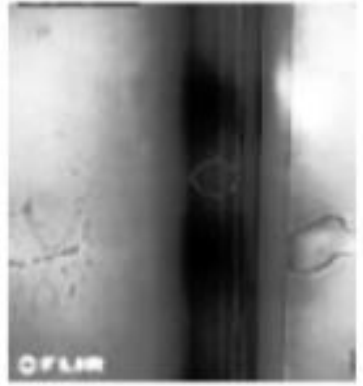

(b)

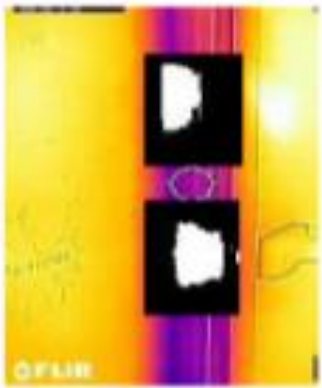

(e)

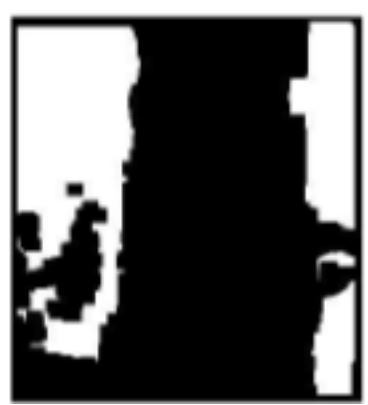

(c)

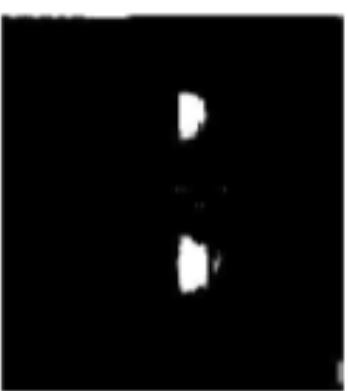

Figure 5. Morphological functions

\section{CONCLUSION}

Thermal images can be used to identify the cold air leak location of cold storage by analyzing the images, which helps to predict early, the cold air leakages and prevent further energy loss. Four methods have been used for the thermal image analysis. It is observed that all four methods are useful. In that, the histogram method helps identifying a leak location. However, the other three methods help in extracting the region of interest by enhancing the leak location. In future, it is recommended that the analysis has to be done by taking images from inside the cold storage and finding the heat transmission into cold storage from outside. Moreover, image classification algorithm should be made for detailed analysis and improve the accuracy of results. 


\section{REFERENCES}

[1] Barbosa-Cánovas, U.V. , Fernández-Molina, J. J. , Alzamora, S. M. , Tapia, M. S., et al., Handling and Preservation of Fruits and Vegetables by Combined Methods for Rural Areas, Technical Manual FAO Agricultural Services Bulletin 149 Food and Agriculture Organization Of The United Nations Rome, 2003.

[2] Tashtoush, B. "Natural losses from vegetable and fruit products in cold storage," Food Control, vol. 11, no. 6, pp. 465-470, 2000.

[3] Chen, P., Cleland, D.J.Lovatt, S. J .,Bassett, M.R “Air infiltration into refrigerated stores through rapid-roll doors," Proc. of the 20th International Congress of Refrigeration, pp. 19-24, Sydney, Australia., 1999.

[4] Ligtenburg, P.J.J.H., \& Wijffels. D.J. "Innovative air curtains for frozen food stores," Proceedings of the 19th International Congress of Refrigeration, pp. https://www.researchgate.net/publication/287772728_Innovative_air_curtains_for_frozen_food_stores, 1995.

[5] Foster, A., Barrett, R., James, S., \& Swain, M. "Measurement and prediction of air movement through doorways in refrigerated rooms," International Journal of Refrigeration, vol. 25, no. 8), pp. 1102-1109, 2002.

[6] Evans, J. A., Hammond, E. C., Gigiel, A. J., Fostera, A. M., Reinholdt, L., Fikiin, K., \& Zilio, C. "Assessment of methods to reduce the energy consumption of food cold stores," Applied Thermal Engineering, vol. 62, no. 2), pp. 697-705, 2014.

[7] Tian, S., Shao, S., \& Liu, B. "Investigation on transient energy consumption of cold storages: Modeling and a case study," Energy, vol. 180, pp. 1-9, Aug 2019.

[8] Wang, C., He, Z., Li, H., Wennerstern, R., \& Sun, Q. "Evaluation on Performance of a Phase Change Material Based Cold Storage House," Energy Procedia, vol. 105, pp. 3947-3952, 2017.

[9] Jadin, M. S., \& Taib, S. "Recent progress in diagnosing the reliability of electrical equipment by using infrared thermography," Infrared Physics \& Technology, vol. 55, no. 4, pp. 236-245, 2012.

[10] Duan, Y., Huebner, S., Hassler, U., Osman, A., Ibarra-Castanedo, C., \& Maldague, X. P. V. "Quantitative evaluation of optical lock-in and pulsed thermography for aluminum foam material," Infrared Physics \& Technology, vol. 60, pp. 275-280, 2013.

[11] Omar, M., Hassan, M. I., Saito, K., \& Alloo, R. "IR self-referencing thermography for detection of in-depth defects," Infrared Physics \& Technology, vol. 46, no. 4, pp. 283-289, 2005.

[12] Aggelis, D. G., Kordatos, E. Z., Soulioti, D. V., \& Matikas, T. E. "Combined use of thermography and ultrasound for the characterization of subsurface cracks in concrete," Construction and Building Materials, vol. 24, no. 10, pp. 1888-1897, 2010.

[13] National Horticulture Board, "Technical Standards and protocol for the cold chain in India, Cold chain development centre,” India. http://nhb.gov.in/documents/cs2.pdf.Accesed on June 13,2019, 2010.

[14] Akdemir. S., "Evaluation of cold storage insulation by thermal images analysis," Bulg. J. Agric. Sci., vol. 20, pp. 246-254, 2014.

[15] Akdemir.S., "Designing of Cold Stores and Choosing of Cooling System Elements," Journal of Applied Sciences, vol. 8, no. 5, pp. 8788-8794, 2008.

[16] Kumar, U. S., \& Sudharsan, N. M. "Enhancement techniques for abnormality detection using thermal image," The Journal of Engineering, vol. 5, pp. 279-283, 2018 